\title{
Thermogravimetric Analysis of Single-Particle RDF Combustion
}

\author{
Dwi Aries Himawanto ${ }^{1}$ Indarto $^{2}$, Harwin Saptoadi ${ }^{2} \&$ Tri Agung Rohmat ${ }^{2}$ \\ ${ }^{1}$ Department of Mechanical Engineering, Sebelas Maret University, Indonesia \\ ${ }^{2}$ Department of Mechanical and Industrial Engineering, Gadjah Mada University, Indonesia \\ Correspondence: Dwi Aries Himawanto, Department of Mechanical Engineering, Sebelas Maret University Jalan \\ Ir. Sutami no.36A Surakarta, Indonesia. Tel: 62-271-632-163. E-mail: dwi_ah@uns.ac.id
}

Received: September 12, 2013

Accepted: October 4, 2013 Online Published: October 18, 2013

doi:10.5539/mas.v7n11p33

URL: http://dx.doi.org/10.5539/mas.v7n11p33

\begin{abstract}
An alternative to solve the problem of energy supply is to find the renewable energy sources which have abundant reserves. Municipal Solid Wastes (MSW) can be one of the solutions to form a Refused Derived Fuels (RDF) such as MSW char briquette through pyrolysis and densification processes. In this work, thermogravimetry analysis has been performed to analyze the combustion characteristic of MSW char briquette. The sample was made by $70 \%$ wt. of the MSW organic components and $30 \%$ wt. of the MSW non organic components. 20 grams of the sample were heated in the reactor whose temperature was increased by $10{ }^{\circ} \mathrm{C} / \mathrm{min}$ from room temperature to $400{ }^{\circ} \mathrm{C}$. The samples were then held for 30 minutes before it was cooled down to room temperature. Approximately, 100 $\mathrm{ml} / \mathrm{min}$ of the nitrogen gas was introduced from the bottom of the reactor as a swept gas. Three grams of the produced char obtained from earlier processes were densified using $20 \% \mathrm{wt}$. cassava starch used as binder to form a briquette. The densification was conducted using a working pressure of $250 \mathrm{~kg} / \mathrm{cm} 2$ which held for 1 minute. The densified sample was then dried in the furnace at $105^{\circ} \mathrm{C}$ for 15 minutes. The briquette was placed in the furnace whose temperature was increased by a selected heating rate until the mass of the sample was nearly constant. The results showed that the burning profiles of RDF could not be approached directly from the summing of a single component, because it involved a lot of parameters that play a role in the combustion processes. Compared with the experimental results, the calculation of the combustion activation energy showed significant differences. The other result showed that the briquette combustion could be approximated by a Shrinking Core Model (SCM).
\end{abstract}

Keywords: MSW, pyrolysis, thermogravimetry, combustion

\section{Background}

The increasing demand of energy forces the exploration of new and renewable energy sources. One of the energy sources having abundant reserves is Municipal Solid Waste (MSW). Suitable technology to extract the energy from the wastes is still under research. Advanced researchs are required because the conversion process must be a green technology to accommodate the environmental requirement. The basic problem of MSW treatment is that they are produced in a huge amount with highly varied compositions. The compositions of MSW in one country are different from that of the others. Currently, Indonesia produces approximately 36.5 billion tons of municipal solid wastes. One of the alternative technologies to convert the wastes into energy is using pyrolysis, because it can convert the solid wastes into three type of fuels: solids, gaseous and liquids.

Pyrolysis can be defined as a thermochemical conversion of the solid fuels in the absence of oxidizing agents, which results in the conversion of the solid fuels into bio oil, char and gases (Di Blasi, 2008). A pyrolysis of $12 \mathrm{~kg}$ of the dried household refuse performed at a temperature between $500{ }^{\circ} \mathrm{C}$ and $650{ }^{\circ} \mathrm{C}$ could reduce their volumes by approximately $65 \%$ on average and produce a pyrolytic oil between $5.27 \mathrm{~kg}$ and $6.85 \mathrm{~kg}$. Meanwhile, the residues obtained were mainly in the form of char (25\% wt.) (Ojolo \& Bamgboye, 2005).

Packed bed pyrolyser systems, which run under slow pyrolisis conditions, could increase the production of the char produced by segregated municipal solid wastes at around 0.3-1.0 times bigger than those produced by thermogravimetry analyser (Swithenbank et al., 2005). Yang et al. (2007) conducted a slow pyrolysis study of the municipal solid waste in a packed bed pyrolizer with a considerable mass of the sample. Phan et al. (2008) conducted a study on the characterization of the products obtained by the MSW using slow pyrolisis. Thermogravimetric analysis of bamboo char briquette carried out by Himawanto et al. (2011) showed that the pyrolysis conditions influenced the activation energy of the combustion. The studies on the typical Indonesian 
MSW (bamboo wastes, banana leaves wastes, styrofoam wastes and snack wrap wastes) using slow pyrolysis done by Himawanto et al. (2012) showed that bamboo wastes and banana leaves can be catogorized as low stability organics, snack wrapping can be categorized as mixed polymer material, whereas styrofoam wastes can be categorized as plastic materials, the later has high thermal stability. Their studies also found that a global kinetic method could be used to calculate the activation energy of pyrolysis. Cheng et al. (2007) carried out a study on the char combustion characteristics of the municipal solid waste. The pyrolysis was performed at a heating rate of $10{ }^{\circ} \mathrm{C} / \mathrm{min}$ and was subsequently held when the temperature has reached $666^{\circ} \mathrm{C}$. The process was then continued by several combustion tests using the same heating rate. Grammelis et al. (2009) also conducted a research on the process of pyrolysis and combustion of the MSW. The study was conducted using 5 samples of the wood based, 6 samples of the plastic based, and 2 samples of RDF (Refused Derived Fuel). The pyrolysis was carried out at a temperature range between $30^{\circ} \mathrm{C}$ and $1000^{\circ} \mathrm{C}$ using a heating rate of $20^{\circ} \mathrm{C} / \mathrm{min}$, while the combustion process was done at the same temperature conditions. Based on the background mentioned above, the main objective of this work was to look for the correlations between a single component and multi components of the MSW char combustion characteristics.

\section{Experimental Method}

\subsection{Raw Materials}

Four types of waste materials were used as the samples in this work. All materials were obtained in the final dumpsites area in Yogyakarta, Indonesia. The basic reason of the material selections is that the wastes can be directly used as the sample without any additional processes. Referring to Indonesian case in the present study, bamboo and banana leaves represent organic or biodegradable wastes, whereas multi materials (snack wrap and styrofoam) represent non organic wastes.

\subsection{Experimental Method}

The samples preparation was started by drying the materials in order to reduce the moisture content less than $12 \%$ wt. The dried materials were then milled to decrease the size of particle smaller than $0.841 \mathrm{~mm}$.

The reactor used to pyrolyze the samples was manufactured based on the macrobalance introduced by Swithenbank et al. (2005). The schematic configuration of the experimental apparatus can be seen in Figure 1. To make sure that the pyrolysis process was conducted in an inert condition, $0.1 \mathrm{l} / \mathrm{min}$ of nitrogen was kept flowing during the process. The temperature of the reactor was increased by $10{ }^{\circ} \mathrm{C} / \mathrm{min}$. When the temperature of the reactor has reached $400{ }^{\circ} \mathrm{C}$, it was then maintained for 30 minutes.

Three grams of the produced char obtained from earlier processes were densified using $20 \%$ wt. cassava starch used as binder to form a briquette. The densification was conducted using a working pressure of $250 \mathrm{~kg} / \mathrm{cm}^{2}$ which held for 1 minute. The densified sample was then dried in the furnace at $105^{\circ} \mathrm{C}$ for 15 minutes.

Afterwards, the briquette was put in the reactor to examine the combustion characteristics using thermogravimetric method. Air used as oxidizer was streamed at a flow rate of $1 \mathrm{lt} / \mathrm{min}$. The temperature of the reactor was increased by $20{ }^{\circ} \mathrm{C} / \mathrm{min}$ until no mass loss was obtained. The combustion temperature was measured by K-type thermocouple which was spotted on the sample and was connected to the temperature data acquisitions, meanwhile the mass loss data were collected using an analytical balance which placed on the top of the reactor. The data of the temperature and the mass loss were compiled in the computer so that the thermogravimetric graph showing the burning profile of the samples can be analysed and the combustion activation energies can be calculated. 


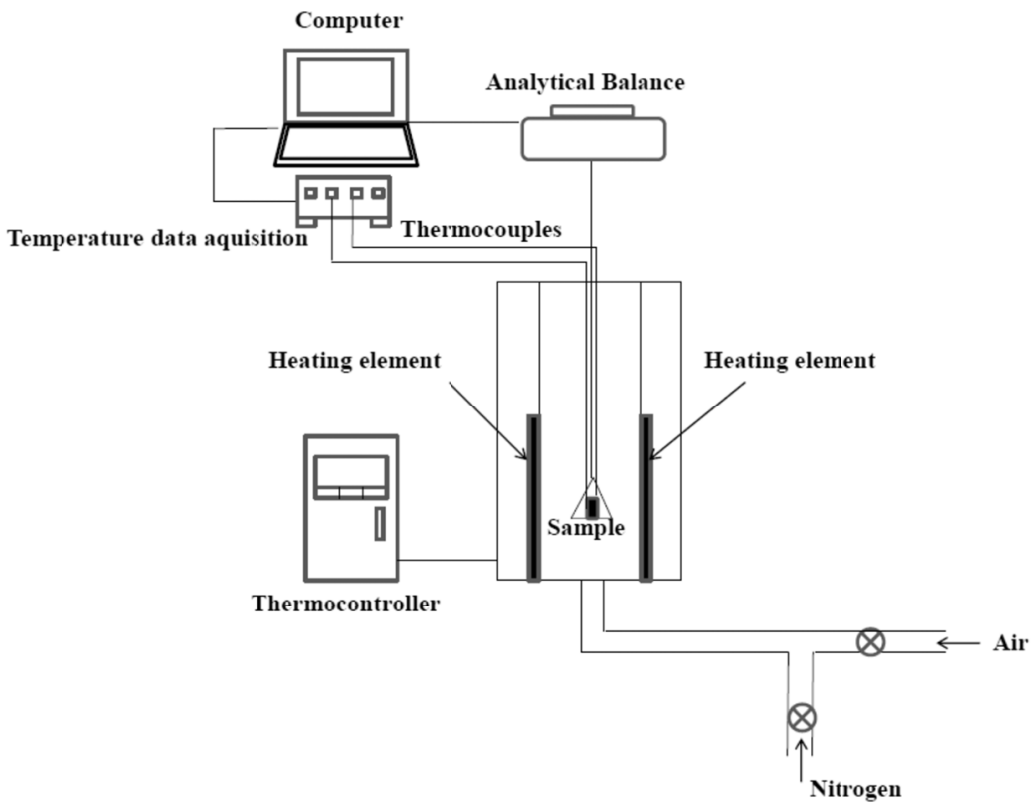

Figure 1. Experimental apparatus

\section{Results and Discussion}

\subsection{Raw Materials Briquette Thermogravimetry Analysis}

The burning profiles could be expressed as the correlation between $\mathrm{m}_{\mathrm{t}} / \mathrm{m}_{\mathrm{o}}$ versus time and the sample temperature versus time, where $m_{t}$ is the mass of the sample at $t$ minute and $m_{o}$ is the mass of the sample at the initial time.

The combustion stages of the bamboo briquette in accordance with the combustion theory of the solid fuels states that the burning of biomass can be divided into three phases. The first stage is the drying which characterized by a slower mass loss. The second stage is the devolatilization which characterized by a larger mass loss. The third stage is the charcoal burning which characterized by a rapid mass loss. Meanwhile, the burning profile of the solid fuels can be divided into four temperature points. The first point is the volatile matter initiation temperature (ITVM) when the mass begins to fall. The second is the initiation temperature when the rate of the mass loss accelerates due to the onset of the char combustion. This stage is also called ITFC (fixed carbon initiation temperature). The third important temperature is the peak temperature (PT) when the rate of the mass loss reaches a maximum value. The last important temperature is the burn out temperature (BT) when the mass becomes constant at the completion of burning.

Figure 2 shows the combustion characteristic of the bamboo briquette. It can be seen that ITVM occurred at $148.5^{\circ} \mathrm{C}$, ITFC was at $289{ }^{\circ} \mathrm{C}$, PT was at $346.6^{\circ} \mathrm{C}$, and BT was at $430.9^{\circ} \mathrm{C}$ (Himawanto et al., 2011). After reaching PT, the temperature of the sample had a tendency to fluctuate. It was alleged that this was caused by a restricted airflow into the sample because the ashes had covered the sample. It also indicates that PT occurred at a relatively low temperatures compared with that of the ITFC. This was caused by the layer of ash around the briquettes that inhibited the air to diffuse into the briquettes. The combustion characteristic of the banana leaf briquettes was also suitable with the combustion theory of solid fuels, as shown in Figure 3. The result shows that ITVM occurred at $228^{\circ} \mathrm{C}$, ITFC was at $457.7^{\circ} \mathrm{C}$, PT was at $416.5^{\circ} \mathrm{C}$, and BT was at $448.7^{\circ} \mathrm{C}$. Surprisingly, the combustion characteristic of the snack waste briquettes shows that PT and BT were absence. This was due to the samples burnt in a short time without producing ash, as shown in Figure 4. Figure 5 shows the combustion characteristic of $70 \mathrm{wt} . \%$ of the organic briquettes. It can be seen that the devolatilization started at $227.8{ }^{\circ} \mathrm{C}$, the char combustion occurred at $307.8^{\circ} \mathrm{C}$, the peak temperature was at $330.1{ }^{\circ} \mathrm{C}$, whereas the burn out temperature started at $493{ }^{\circ} \mathrm{C}$. The charactristic of the temperature profiles is summarized in Table 1. 
Table 1. Burning temperature profiles of the raw materials

\begin{tabular}{lcccc}
\hline \multicolumn{1}{c}{ Samples } & $\begin{array}{c}\text { ITVM } \\
\left({ }^{\circ} \mathbf{C}\right)\end{array}$ & $\begin{array}{c}\text { ITFC } \\
\left({ }^{\circ} \mathbf{C}\right)\end{array}$ & $\begin{array}{c}\text { PT } \\
\left({ }^{\circ} \mathbf{C}\right)\end{array}$ & $\begin{array}{c}\text { BT } \\
\left({ }^{\circ} \mathbf{C}\right)\end{array}$ \\
\hline Bamboo & 148.5 & 289 & 346.6 & 430.9 \\
Banana leaves & 228 & 457.7 & 416.5 & 448.7 \\
Snack wrap & 216.1 & 223 & not available & not available \\
Styrofoam & not available & not available & not available & not available \\
$70 \%$ organic & 227.8 & 307.8 & 330.1 & 493 \\
\hline
\end{tabular}

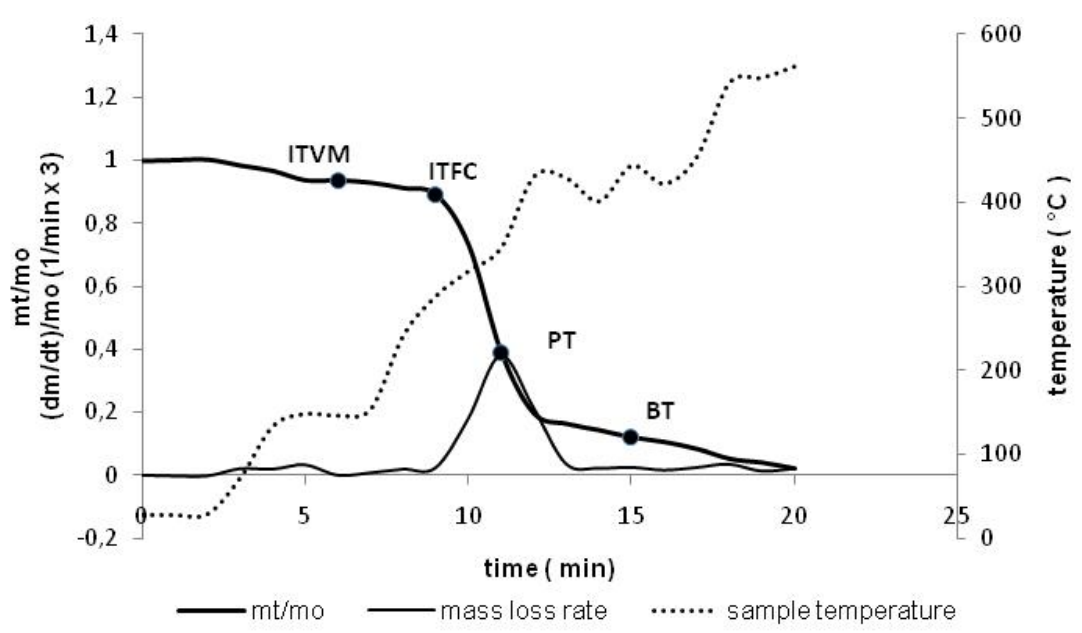

Figure 2. Combustion characteristic of the bamboo briquetes

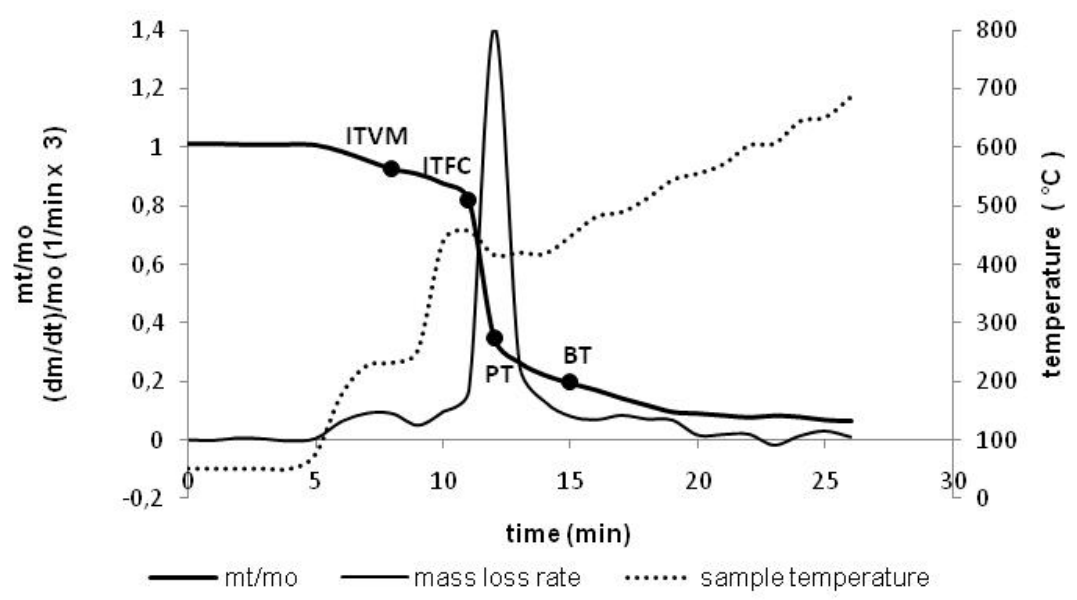

Figure 3. Combustion characteristic of the banana leave briquettes 


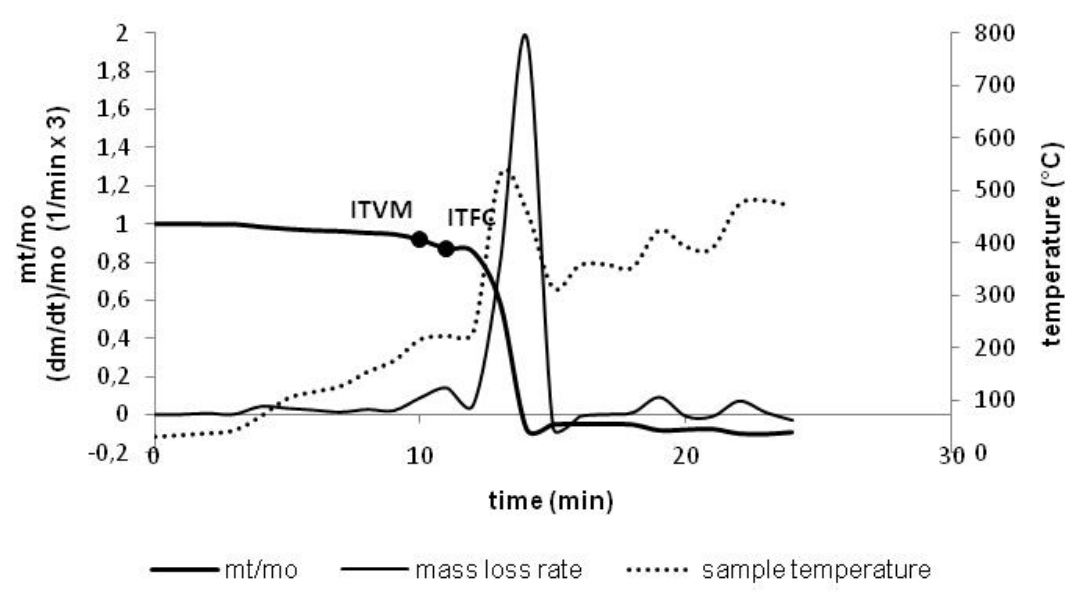

Figure 4. Combustion characteristic of the snack wrap briquettes

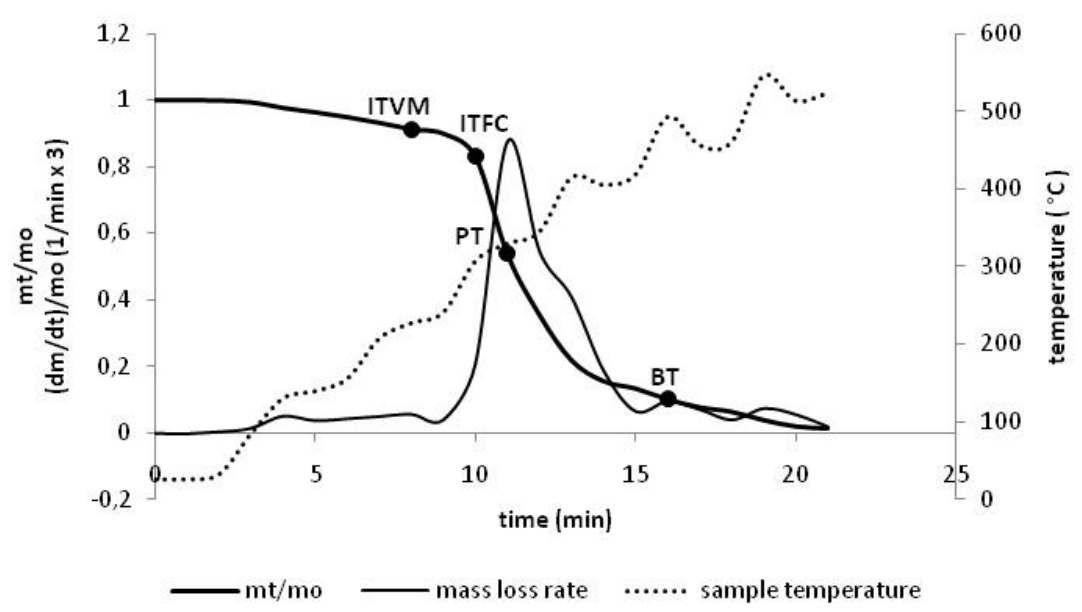

Figure 5. Combustion characteristic of $70 \mathrm{wt} . \%$ of the organic briquette

\subsection{The Effect of Pyrolysis Conditions on the Characteristics of Char Combustion}

In the combustion of char briquette, it was shown that the char combustion and the drying zones occurred in a short time. The remaining mass fluctuated with the sample temperature due to the layer of ash covering the sample inhibited the diffusion of oxygen into the sample and the combustion gases out of the sample. The determination of the combustion temperature when the process started to initiate was difficult. In the char combustion characteristics, it can be seen that there was a clear difference between the combustion characteristics of the char briquette and that of the briquettes without pyrolysis. In the combustion of the char briquettes, the boundary of the three combustion stages was not clear, so that only the temperature of ITFC and PT which could be clearly observed. Figure 6 shows the combustion characteristic of the bamboo char briquettes. The result indicates that ITFC occurred at $195.6{ }^{\circ} \mathrm{C}$ which followed by an increased mass loss, whereas PT occurred at $433.6{ }^{\circ} \mathrm{C}$ (Himawanto et al., 2011). The combustion characteristic of the banana leaves char briquettes can be seen in Figure 7. The result shows that ITFC occurred at $231.9{ }^{\circ} \mathrm{C}$ and PT was at $407{ }^{\circ} \mathrm{C}$. Meanwhile, the combustion characteristic of the snack wrap char briquettes can be seen in Figure 8. The result shows that ITFC was located at $263.7^{\circ} \mathrm{C}$, while PT occurred at $679^{\circ} \mathrm{C}$. Figure 9 shows the combustion characteristic of Styrofoam char briquettes. The result shows that ITFC for styrofoam char briquettes occurred at $280.9^{\circ} \mathrm{C}$, while PT was at $446.5^{\circ} \mathrm{C}$. It also found that ITFC and PT of mixed samples could not be approximated by the sum of the single components as shown in Figure 10. Table 2 shows the sumarry of the burning temperature profiles of the char briquettes. 
Table 2. Burning temperature profiles of the char briquettes

\begin{tabular}{ccc}
\hline Samples & $\begin{array}{c}\text { ITFC } \\
\left({ }^{\circ} \mathbf{C}\right)\end{array}$ & $\begin{array}{c}\text { PT } \\
\left({ }^{\circ} \mathbf{C}\right)\end{array}$ \\
\hline Bamboo & 195.6 & 433.6 \\
Banana leaves & 231.9 & 407 \\
Snack wrap & 263.7 & 679 \\
Styrofoam & 280.9 & 446.5 \\
70\% organic & 241.1 & 407.7 \\
\hline
\end{tabular}

Based on the changes of physical shape of the briquettes before and after the thermogravimetric analysis, which showed that the sample remained cylindrical but with a smaller diameter, it is presumed that the combustion mechanism of the briquettes can be approximated by Shrinking-Core Model (SCM). In this model, the reaction starts to occur at the outer surface of the particle, and the reaction zone will move radially toward the particles after the change of particles that react with ashes. The particle core of unreacted fuel will experience a reduction in size during the reaction. SCM is sufficiently realistic to be used in the combustion model of solid fuels. The appropriate SCM model type in this work is SCM with diffusion-controlled through ash layer, because it was observed during the combustion that the ash remained attached to the samples in the final stage. Meanwhile, from the pattern of fire occurrence, the two-layer burning model can also be used to analyze the studied sample during the combustion process. The basic assumption used is the same as applied in the single layer model with the existence of carbon contained in the surface due to an oxidized CO. Based on the two modelling approaches of the combustion of solid fuel above, it can be concluded that the diffusivity were an important parameter in the combustion process of solid fuels, where the diffusivity is determined by porosity both inside the sample and on the sample surfaces. The present result is supported by a research conducted by Essenhigh et al. (1965) and Fu et al. (1997). They carried out the works using one film model and two film model. Although the effect of porosity of the fuel greatly influences the diffusivity of oxygen to the surface of solid fuels, this factor was not discussed at all in the models. The effect of porosity of the solid fuels during combustion processes was studied by Liu et al. (2000). The combustion model incorporating with the porosity variables was clearly seen in the research conducted by Mori et al. (1999). Based on the present result, it can be said that the combustion of solid fuels are greatly influenced by many factors, particularly the porosity of solid fuels, either on the surface or inside the fuel itself. This is the main reason that the combustion characteristics of a mixture cannot be approximated by the sum of the combustion characteristics of a single component.

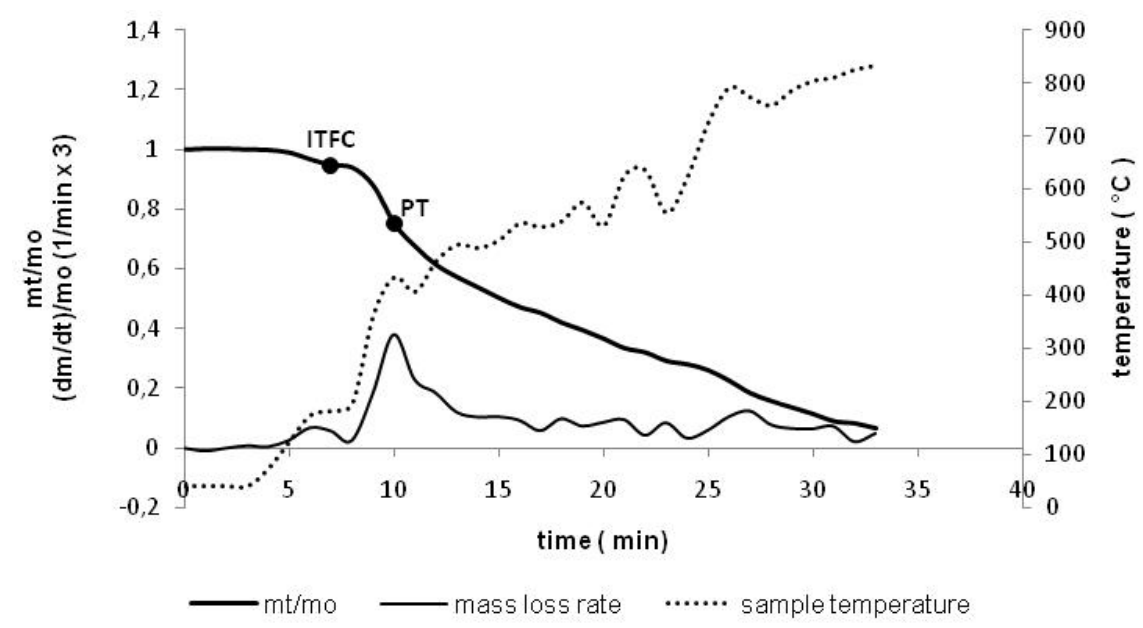

Figure 6. Combustion characteristic of the bamboo char briquettes 


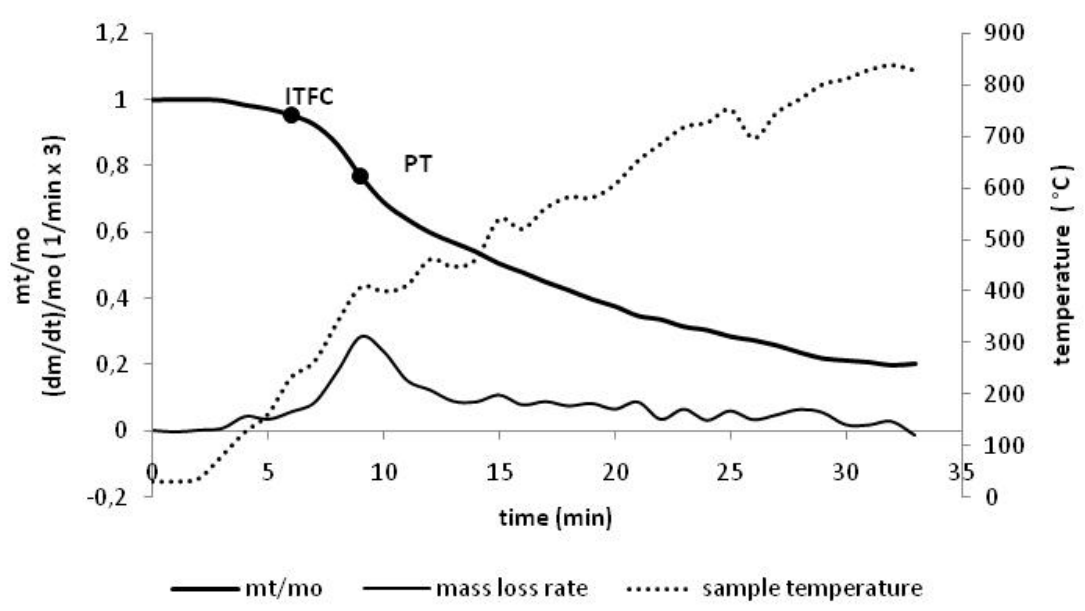

Figure 7. Combustion characteristic of the banana leaves char briquettes

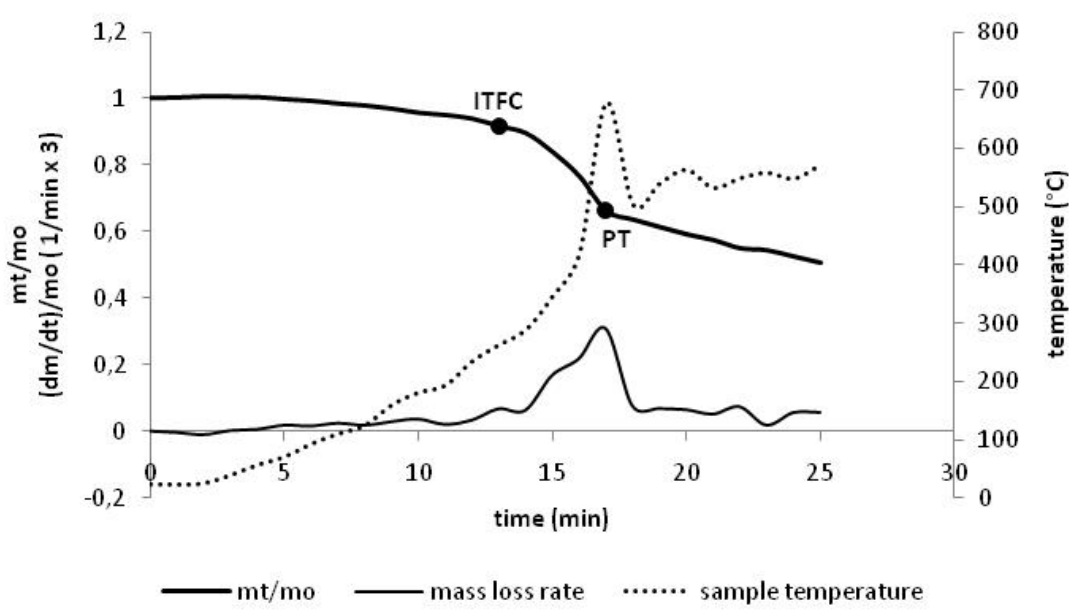

Figure 8. Combustion characteristic of the snack wrap char briquettes

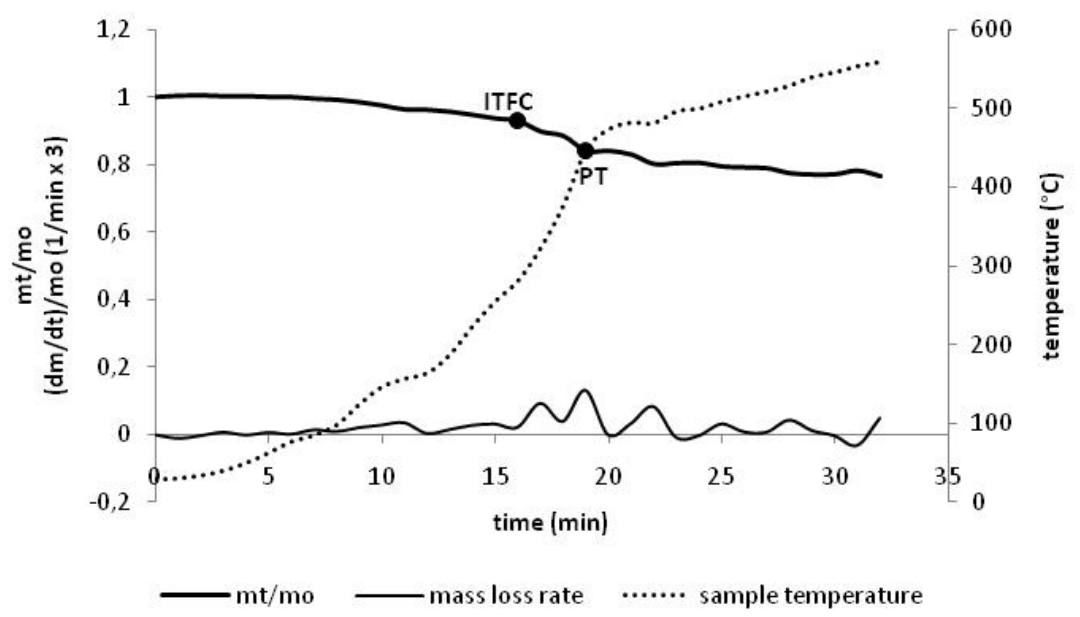

Figure 9. Combustion characteristic of the styrofoam char briquettes 


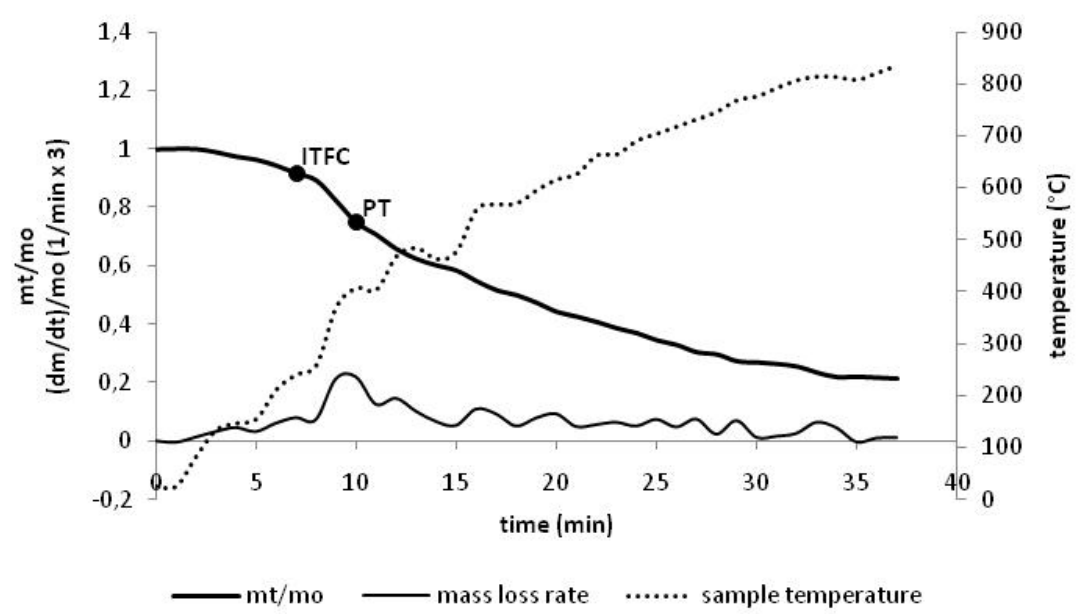

Figure 10. Combustion characteristic of $70 \mathrm{wt} . \%$ organic char briquettes

\subsection{Global Kinetics of Char Briquette Combustion}

Global kinetics in the combustion of char briquettes can be written as follows:

$$
\frac{d x}{d t}=A e^{-\frac{E}{R T}}(1-x)
$$

where $\mathrm{E}$ is the activation energy, $\mathrm{T}$ is the sample temperature, $\mathrm{A}$ is the pre-exponential factor, $\mathrm{t}$ is time, and $\mathrm{x}$ is pyrolysis conversion which can be calculated using Equation (2),

$$
x=\frac{w_{0}-w}{w_{0}-w_{f}}
$$

where $\mathrm{w}$ is the sample mass, $\mathrm{w}_{0}$ is the initial mass of the sample and $\mathrm{w}_{\mathrm{f}}$ is the final mass of the sample.

Using mathematical manipulations, Equation (1) can be expressed as follows:

$$
\ln \left[-\frac{\ln (1-x)}{T^{2}}\right]=\ln \left[\frac{A R}{\beta E}\right]-\frac{E}{R T}
$$

where $\beta$ is the heating rate which was kept constant.

The relationship between $\ln \left[-\frac{\ln (1-x)}{T^{2}}\right]$ and 1/T shows a linear correlation which has a slope equal to $-\mathrm{ER}^{-1}$. The activation energy can be calculated based on the magnitude of the slope. Meanwhile, the pre-exponential factor A can also be determined by taking the temperature at which $w=\frac{\left(w_{0}-w_{f}\right)}{2}$ in the place of $\mathrm{T}$ in the intercept term of Equation (3).

Table 3 shows the calculation results of the activation energies for all samples. The result indicates that the activation energy of the char briquette were generally lower than that of its raw materials, except the banana leaves char briquettes which contained no devolatilization process. In the banana leaves char briquettes, the activation energy of the char was higher than that of its raw material. This was presumably due to the high percentage of the ash content. 
Table 3. The activation energy of the briquette combustion

\begin{tabular}{cccc}
\hline Samples & Samples Condition & $\begin{array}{c}\text { Activation energy } \\
\text { E (kJ/mol) }\end{array}$ & $\begin{array}{c}\text { Pre Exponential Factor } \\
\text { A (1/ min) }\end{array}$ \\
\hline \multirow{2}{*}{ Bamboo $^{*}$} & Raw material & 62.9 & $6,040.90$ \\
& Char & 21.7 & 0.5 \\
Banana leaves & Raw material & 17.1 & 1.2 \\
& Char & 23.1 & 3.5 \\
Snack wrap & Raw material & 50.9 & 190.3 \\
& Char & 25.8 & 1.4 \\
Styrofoam & Raw material & not available & not available \\
& Char & 30.2 & 14.48 \\
70\% organic & Raw material & 31.3 & 51.38 \\
& Char & 30.3 & 5.7 \\
\hline
\end{tabular}

*Source: Himawanto et al. (2011).

Calculation of the activation energy of the char combustion was difficult because of the char morphology and the wide range of firing rates (Wornat et al., 1996). Hart et al. (2001) examined the reactivity of the burning briquettes and found that the temperature of samples increased with the increasing temperature of the furnace. However, the firing rate decreased because of the increasing layer thickness of the ash on the briquettes surfaces, which in turn, inhibited the diffusion of oxygen and combustion gases into and out of briquettes, respectively. The rate of mass loss was high in the early stages of combustion due devolatilisation process. Fluctuations in the rate of mass loss at high temperature occurred because of the loose ash from the briquettes, while the lower temperature occurred at the end of char combustion associated with a decrease in the firing rate caused by the ash layer. The activation energy of the char combustion obtained by predictive calculations and the experimental results was $46.7 \mathrm{~kJ} / \mathrm{mol}$ and $30.3 \mathrm{~kJ} / \mathrm{mol}$, respectively. Thus, the difference between prediction and experimental result was $56.04 \%$. The predictive values of the activation energy were calculated from the sum weighting theory which the mass loss was approached directly from the summing of a single component. This difference, as discussed in the previous section, was most likely due to the briquettes porosity which continued to change during the combustion process.

\section{Conclusions}

Based on the result obtained in the present work, it can be concluded that the application of thermogravimetric analysis on the organic component of raw material briquettes could provide a complete combustion profile of the sample such as ITVM, ITFC, PT and BT. However, the burning profiles of the char briquettes could only be used to predict ITFC and PT. The burning profiles of solid fuels (ITVM, ITFC, PT and BT) could not be approached directly from the summing of a single component due to many factors affecting the combustion process. In the calculations of activation energy for the char combustion, the predicted results gave a difference of approximately $56.04 \%$ when compared with the experimental results. The results also showed that the briquette combustion could be estimated by a Shrinking Core Model (SCM) so that the diffusion of air into briquettes, briquette porosity and the characteristics of the ash greatly affected the combustion process.

\section{Acknowledgments}

This work was a part of Competitive Research Grant in 2009-2010 research program, funded by the Directorate General of Higher Education, Ministry of National Education RoI. The main author also expresses his gratitude to all research assistants.

\section{References}

Cheng, Z., Chen, H., Zhang, Y., Hack, P., \& Pan, W. P. (2007). An Application of Thermal Analysis to Household Waste. Journal of ASTM International, 4(1). http://dx.doi.org/10.1520/JAI100523

Di Blasi, C. (2008). Modeling Chemical and Physical Processes of Wood and Biomass Pyrolisis. Progress in Energy and Combustion Science, 34, 47-99. http://dx.doi.org/10.1016/j.pecs.2006.12.001 
Essenhigh, R. H., Froberg, R., \& Howard, J. B. (1965). Combustion Behavior of Small Particles. Industrial and Engineering Chemistry, 57(9), 32-43. http://dx.doi.org/10.1021/ie50669a007

Fu, W. B., Zhang, B. L., \& Zheng, S. M. (1997). A Relationship Between the Kinetic Parameters of Char Combustion and the Coal's Properties. Combustion and Flame, 109, 587-598. http://dx.doi.org/10.1016/S0010-2180(97)89632-0

Grammelis, P., Basinas, P., Malliopoulou, A., \& Sakellaropoulos, G. (2009). Pyrolisis Kinetics and Combustion Characteristics of Waste Recovered Fuels. Fuel, 88, 195-205. http://dx.doi.org/10.1016/j.fuel.2008.02.002

Himawanto, D. A., Indarto, Saptoadi, H., \& Rohmat ,T. A. (2012). Thermogravimetric Analysis and Global Kinetics of Segregated MSW Pyrolysis. Modern Applied Science, 6(1), 120-130. http://dx.doi.org/10.5539/mas.v6n1p120

Himawanto, D. A., Indarto, Saptoadi, H., Rohmat, T. A., \& Pratama, S. R. (2011). Analisa Thermogravimetry Pembakaran Briket Char Bambu. Jurnal Teknik Mesin, 11(1), 77-85.

Hurt, S., Ward, J., \& Biffin, M. (2001). Development of A Method to Assess The Reactivity of Multi Component Solid Fuel Briquettes. IFRF Combustion Journal, article number 200106. Retrieved from $\mathrm{http}: / / \mathrm{www}$.industrial.combustion.ifrf.net/view_paper.html?paperId=26

Liu, G., Benyon, P., Benfell, K. E., Bryant, G. W., Tate, A. G., Boyd, R. K., ... Wall, T. F. (2000). The Porous Structure of Bituminus Coal Chars and Its Influence on Combustion and Gasification Under Chemistry Controlled Conditions. Fuel, 79, 617-626. http://dx.doi.org/10.1016/S0016-2361(99)00185-4

Mori, T., Miyauchi, K., Maeno, Y., Aoki, H., \& Miura, T. (1999). A Numerical Study on the Combustion of a Low Temperature Carbonized Semi-coke Particle. ISIJ International, 39, 896-904. http://dx.doi.org/10.2355/isijinternational.39.896

Ojolo, S. J., \& Bamgboye, A. I. (2005). Thermochemical Conversion of Municipal Solid Waste to Produce Fuel and Reduce Waste. Agricultural Engineering International: the CIGR Ejournal, 7. Retrieved from http://ecommons.library.cornell.edu/handle/1813/10437

Phan, A. N., Ryu, C., Sharifi, V. N., \& Swithenbank, J. (2008). Characterisation of Slow Pyrolisis Products from Segregated Wastes for Energy Production. J. Anal. Appl. Pyrolisis, 81, 65-71. http://dx.doi.org/10.1016/j.jaap.2007.09.001

Swithenbank, J., Sharifi, V. N., \& Ryu, C. (2005). Waste Pyrolisis and Generation of Storable Fuel. SUWIC Department of Chemical and Process Engineering, The University of Sheffield.

Wornat, M. J., Hurt, R. H., Davis, K. A., \& Yang, N. Y. C. (1996). Single Particle Combustion of Two Biomass

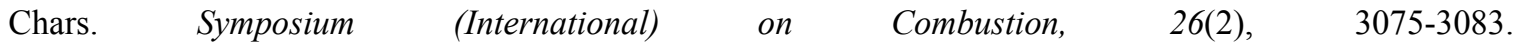
http://dx.doi.org/10.1016/S0082-0784(96)80151-2

Yang, Y. B., Phan, A. N., Ryu, C., Sharifi, V., \& Swithenbank, J. (2007). Mathematical Modelling of Slow Pyrolisis of Segregated Solid Waste in A Packed-Bed Pyroliser. Fuel, 86, 169-180. http://dx.doi.org/10.1016/j.fuel.2006.07.012

\section{Copyrights}

Copyright for this article is retained by the author(s), with first publication rights granted to the journal.

This is an open-access article distributed under the terms and conditions of the Creative Commons Attribution license (http://creativecommons.org/licenses/by/3.0/). 